\title{
Overview of literature on RMC and applications to Tanzania
}

\author{
Karline Wilson-Mitchell ${ }^{1 *}$ (D, Lucia Eustace ${ }^{2}$, Jamie Robinson ${ }^{3}$, Aloisia Shemdoe ${ }^{2}$ and Stephano Simba ${ }^{2}$
}

\begin{abstract}
Respectful maternity care research in Tanzania continues to increase. This is an overview of the literature summarizing research based on the domains which comprise this quality of care indicator, ranging from exploratory and descriptive to quantitative measurements of birth perinatal outcomes when respectful interventions are made. The domains of respectful care are reflected in the seven Universal Rights of Childbearing Women but go further to implicate facility administrators and policy makers to provide supportive infrastructure to allay disrespect and abuse.

The research methodologies continue to be problematic and several ethical cautions restrict how much control is possible. Similarly, the barriers to collecting accurate accounts in qualitative studies of disrespect require astute interviewing and observation techniques. The participatory community-based and the critical sociology and human rights frameworks appear to provide a good basis for both researcher and participants to identify problems and determine possible solutions to the multiple factors that contribute to disrespect and abuse. The work-life conditions of midwives in the Global South are plagued with poor infrastructure and significantly low resources which deters respectful care while decreasing retention of workers. Researchers and policy-makers have addressed disrespectful care by building human resource capacity, by strengthening professional organizations and by educating midwives in low-resource countries. Furthermore, researchers encourage midwives not only to acquire attitudinal change and to adopt respectful maternity care skills, but also to emerge as leaders and change agents. Safe methods for conducting care while addressing low resources, skilled management of conflict and creative innovations to engage the community are all interventions that are being considered for quality improvement research. Tanzania is poised to evaluate the outcomes of education workshops that address all seven domains of respectful care.
\end{abstract}

Keywords: Respectful maternity care, Quality improvement, Global health, Maternity care, Midwives

\section{Plain English Summary}

Respectful maternity care (RMC) is a growing field of research and practice which recognizes that effective care must uphold the dignity of the birthing women. How women are treated during pregnancy and labour affects their birth experience and the health of mother and baby. Disrespectful care is a recognized problem worldwide. In low resource settings and/or areas with high mortality, such as Tanzania, disrespectful care directly impacts women's willingness and ability to access health care and give birth with a skilled health worker present.

\footnotetext{
* Correspondence: k.wilsonmitchell@ryerson.ca

${ }^{1}$ Midwifery Education Program, Ryerson University, 350 Victoria Street,

Toronto, ON M5B 2K3, Canada

Full list of author information is available at the end of the article
}

In seeking to address maternal mortality, the focus is often on material circumstances (accessibility of care, economic circumstances); the RMC movement centers the birthing women's experience as a key driver of birth outcomes.

The RMC movement seeks to provide common language for categorizing key themes in disrespectful care. There are seven key pillars (or domains) of RMC. Understanding how RMC impacts women's health is essential to educate governments, health workers, and the global health industry about the importance of quality and dignity in the provision of care. Equally important, we must understand the physical, systemic, and emotional spaces that generate disrespectful care. In our personal experience of hosting RMC workshops in

(c) The Author(s). 2018 Open Access This article is distributed under the terms of the Creative Commons Attribution 4.0 International License (http://creativecommons.org/licenses/by/4.0/), which permits unrestricted use, distribution, and 
Tanzania, we learned firsthand from midwives and nurses about the material and temporal deprivations that shape their context. This literature review provides a broad overview of RMC issues addressed in current research and applications from our experience in Tanzania for practitioners seeking to enable dignified birth and improve birth outcomes in Sub-Saharan Africa and globally.

\section{Background}

Respectful maternity care (RMC) is a growing field of research and practice which recognizes that to be effective, health care and assistance during pregnancy and birth must uphold the dignity of the birthing women. How women are treated during pregnancy and labour affects their birth experience and the health of mother and baby. Disrespectful care is a recognized problem worldwide. In low resource settings such as Tanzania, where there is a high maternal mortality of approximately 410
526 per 100,000 pregnancies [1, 2], disrespectful care directly impacts women's willingness and ability to access health care and give birth with a skilled health worker. In contrast to projects which focus on material circumstances (accessibility of care, economic circumstances) to address maternal mortality; the RMC movement centers the birthing women's experience as a key driver of birth outcomes.

The RMC movement seeks to provide common language to categorize key themes in disrespectful care. Despite varied opinions about defining 'respectful care', researchers and practitioners have developed a rigorous and comprehensive rubric focused on seven domains of RMC (See Table 1). These 12 domains reflect seven Universal Rights of Childbearing Women [3].

Understanding how RMC impacts women's health is essential to educate governments, health workers, and the global health industry about the importance of quality and dignity in the provision of care. Equally

Table 1 Domains of respectful maternity care framework

\begin{tabular}{|c|c|c|}
\hline $\begin{array}{l}\text { Domain } \\
\text { Number }\end{array}$ & Domain Description of Disrespect and Abuse & Universal Childbirth Right \\
\hline 1 & $\begin{array}{l}\text { Physical abuse (e.g., painful or embarrassing procedures without } \\
\text { warning or unnecessarily performed) }\end{array}$ & 1. freedom from harm and ill treatment \\
\hline 2 & $\begin{array}{l}\text { Non-consented care (e.g. lacks provision of information to make an } \\
\text { intelligent decision, lack of permission or courtesy for invasive and } \\
\text { traumatic procedures) }\end{array}$ & 2. informed consent and refusal and respect for choices \\
\hline 3 & $\begin{array}{l}\text { Non-confidential care (e.g., lack of covering to provide culturally } \\
\text { desired modesty, inappropriate sharing of client's information, } \\
\text { inability to track or secure patient records) }\end{array}$ & 3. right to privacy and confidentiality \\
\hline 4 & Non-dignified care (e.g. verbal abuse, psychological abuse) & 4. right to dignity and respect \\
\hline 5 & $\begin{array}{l}\text { Discrimination based on specific attributes (e.g. lack of equitable } \\
\text { maternity care regardless of group membership) }\end{array}$ & 5. equality, freedom from discrimination and equitable care \\
\hline 6 & $\begin{array}{l}\text { Abandonment or denial of highest quality of care available (e.g., } \\
\text { Provision of efficient and effective care) }\end{array}$ & 6. Access to healthcare and the highest attainable level of health \\
\hline 7 & $\begin{array}{l}\text { Detention of mother or baby in facilities (e.g., for lack of payment, } \\
\text { lack of universal access to care) }\end{array}$ & 7. liberty, autonomy, self-determination, and freedom from coercion \\
\hline 8 & Enhancing quality of physical environment and resources & 6. Access to healthcare and the highest attainable level of health \\
\hline 9 & Engaging with effective communication & $\begin{array}{l}\text { 4. right to dignity and respect and 5. equality, freedom from } \\
\text { discrimination and equitable care }\end{array}$ \\
\hline 10 & $\begin{array}{l}\text { Availability of competent and motivated human resources, inability } \\
\text { to provide continuity of care and continuity of carer (e.g., less than } \\
\text { optimal staffing, poor fiscal management, poor recruitment and } \\
\text { retention of personnel, loss of morale and lack of workforce job } \\
\text { satisfaction, poor remuneration for work, poor working conditions } \\
\text { and policies, lack of emotional and professional support for staff, lack } \\
\text { of staff training) }\end{array}$ & 6. Access to healthcare and the highest attainable level of health \\
\hline 11 & $\begin{array}{l}\text { Restriction from movement or position changes, disempowering or } \\
\text { inequitable behaviours or policies (denying the client a culturally safe } \\
\text { space) }\end{array}$ & 4. right to dignity and respect \\
\hline 12 & $\begin{array}{l}\text { Lack of support for desires and choices (e.g. having a labour support } \\
\text { person present at birth, declining a test or procedure, policies at the } \\
\text { facility or governmental level that do not support the desire of } \\
\text { mother to be accompanied by a desired family member or partner, } \\
\text { lack of support for the special psychosocial needs of adolescents or } \\
\text { other vulnerable populations) }\end{array}$ & $\begin{array}{l}\text { 2. informed consent and refusal and respect for choices and } \\
\text { preferences even when the choice is to reject recommended } \\
\text { community standards }\end{array}$ \\
\hline
\end{tabular}


important, are the physical, systemic, and emotional spaces that generate disrespectful care. In our personal experience of hosting RMC workshops in Tanzania, we learned firsthand from midwives and nurses about the material and temporal deprivations that shape their context. This literature review provides a broad overview of RMC as an emerging field, current research and applications to our experience in Tanzania for practitioners seeking to enable dignified birth and improve birth outcomes in Sub-Saharan Africa and globally.

\section{Methods}

Studies and policy papers were on CINHAL, Medline, Pubmed, Proquest, Google Scholar, and Mendeley research databases as described by Arksey and O'Malley (2005) using terms: "developing countries, midwifery, life change events, global health, childbirth rights, adolescents and respectful maternity care". A total of 32 studies and policy papers were found by using some of the elements of Arksey and O'Malley's methods to identify research gaps in existing literature by identifying: 1 . the research question, 2. Relevant studies that had an African or low-resource country-context. 3. Significant findings that we could collate, summarize and compare (see Fig. 1). Of these 32 studies, 16 are critically appraised in Table 2. Following are the three themes emerging from the overview: conceptualization and measurement, worklife experience of providers, leadership and change.

\section{Conceptualization of respectful care}

Respectful care is emerging as a phenomenon of study since the World Health Organization (WHO) concept ualization was published in 2015 [4]. The White Ribbon Alliance operationalized the conclusions of the WHO into seven domains or standards of disrespectful care in the Universal Rights of Childbearing Women. Across the RMC literature reviewed, the authors found wide acceptance of these categories.

While there is some early foundational work on RMC dating back to the early 2000s [5], a majority of the literature reviewed was published after 2010 (See Table 2). We noted a rising spike in publications on this topic, including the WHO conceptualization in 2015 and a Lancet special issue in 2016 [4, 6]. As might be expected for a new field of research, much of the literature reflects the preliminary nature of our understanding of RMC. Investigators for case and field studies such as Rosen et al. [7] noted that study designs were pilots and much of the work sought to solidify and validate the domains of RMC. A more recent systematic review by Shakibazadeh et al. confirms previous reviews that capture the global nature of disrespect and abuse; but they go further to identify a total of 12 relational and infrastructural domains, thereby making the facility managers just as culpable in

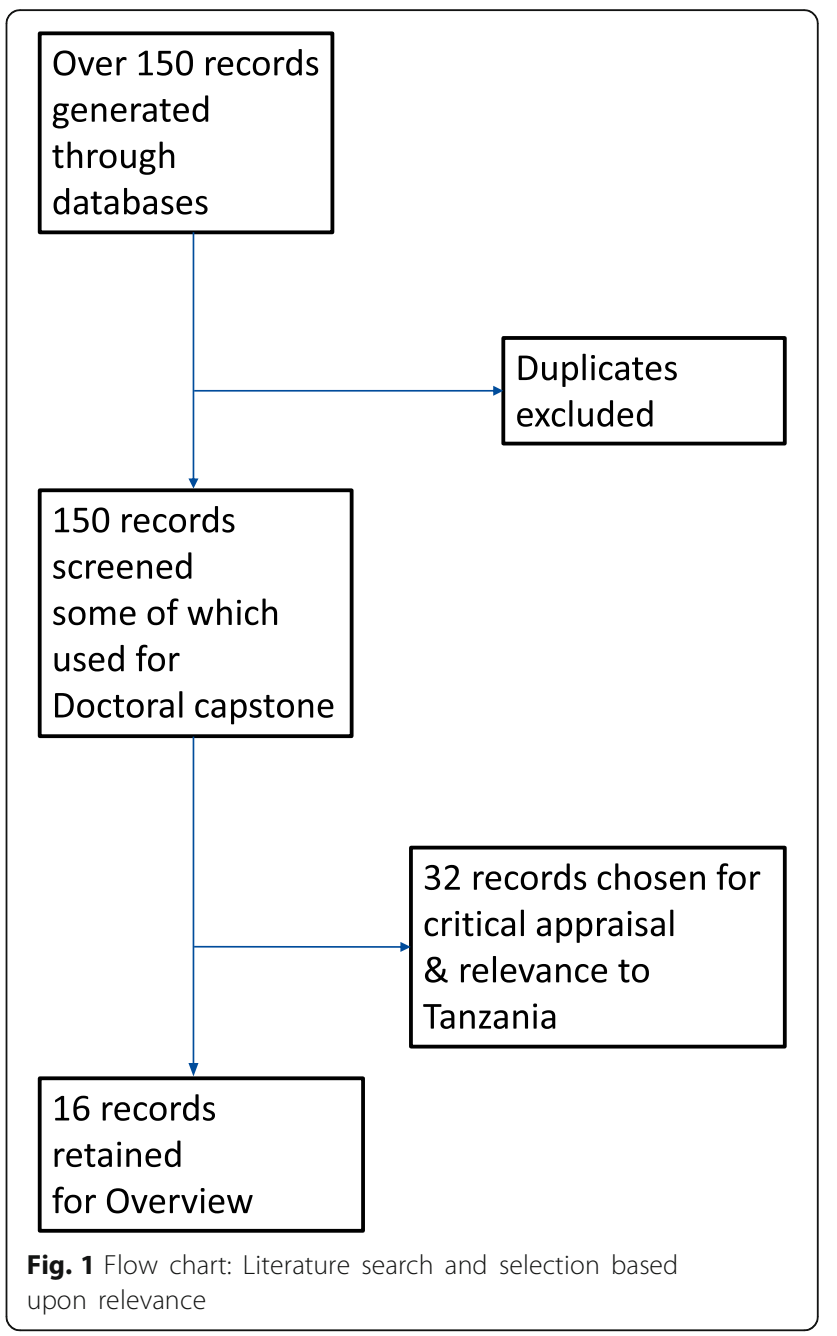

disrespect and abuse. [8] Of note, there are a growing number of observational, descriptive and mixed methods RMC studies specific to Tanzania. [6, 9-15].

We note that although disrespectful care is observed worldwide, in both the Global North as well as the Global South, disrespectful care by maternal care providers has been studied primarily in low-resource countries such as the Dominican Republic [16], India [5, 17], Kenya [18, 19], Peru, Burundi [5], Nigeria, and Tanzania [5, 7, 19, 20].

Work documenting disrespectful care contributes to an overall understanding of the subject and suggests methods for quantifying and comprehending the scale of disrespectful care, a first step to combating it.

There is also a growing body of work suggesting and evaluating interventions to improve the quality of care and identifying the conditions that promote respectful care but little in the way of evidence-based clinical guidelines [6]. In contrast, the systematic review by Prost et al. [21] and the study by Bhutta et al. [22] demonstrate that interventions such as deploying community 


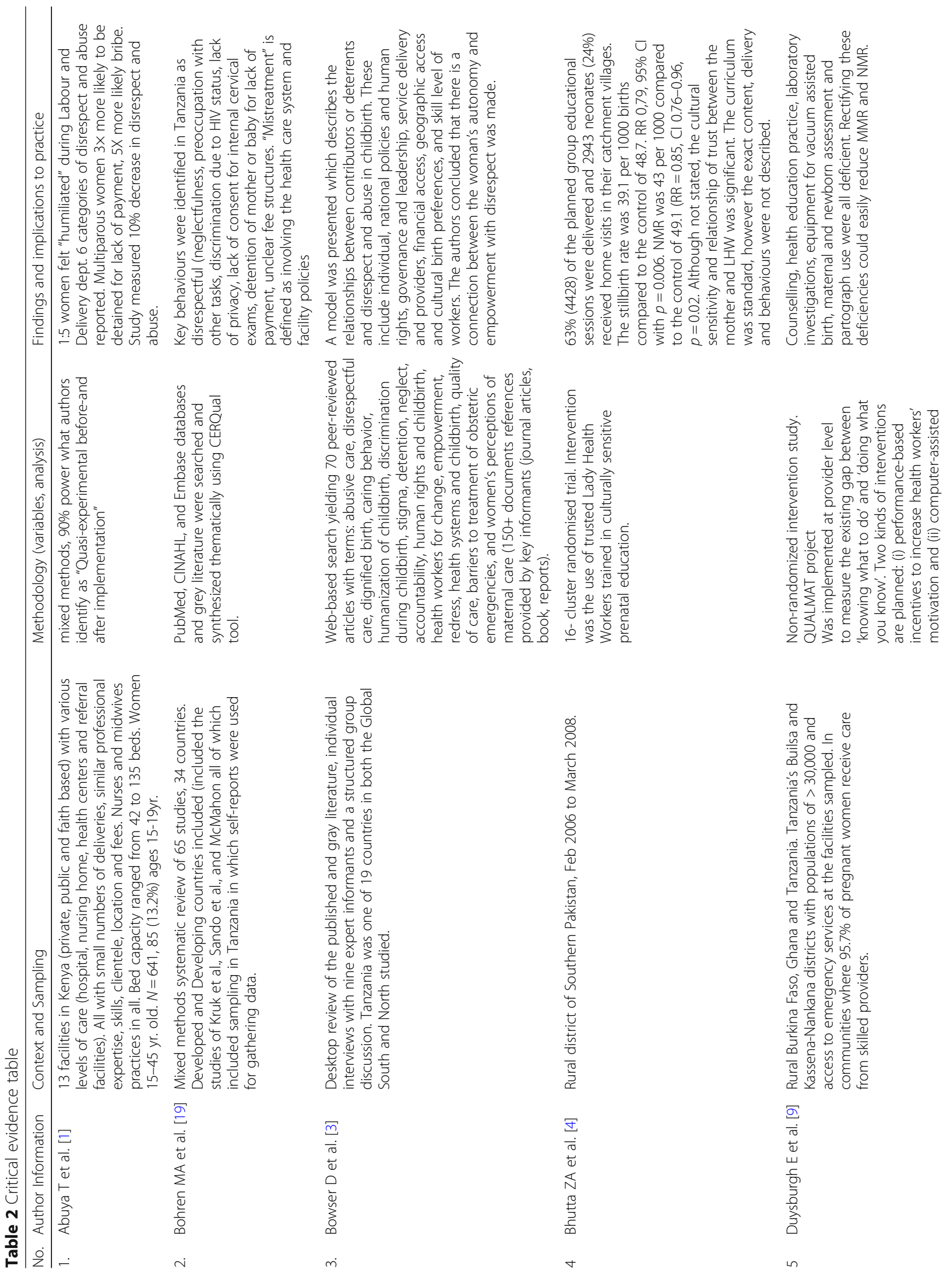



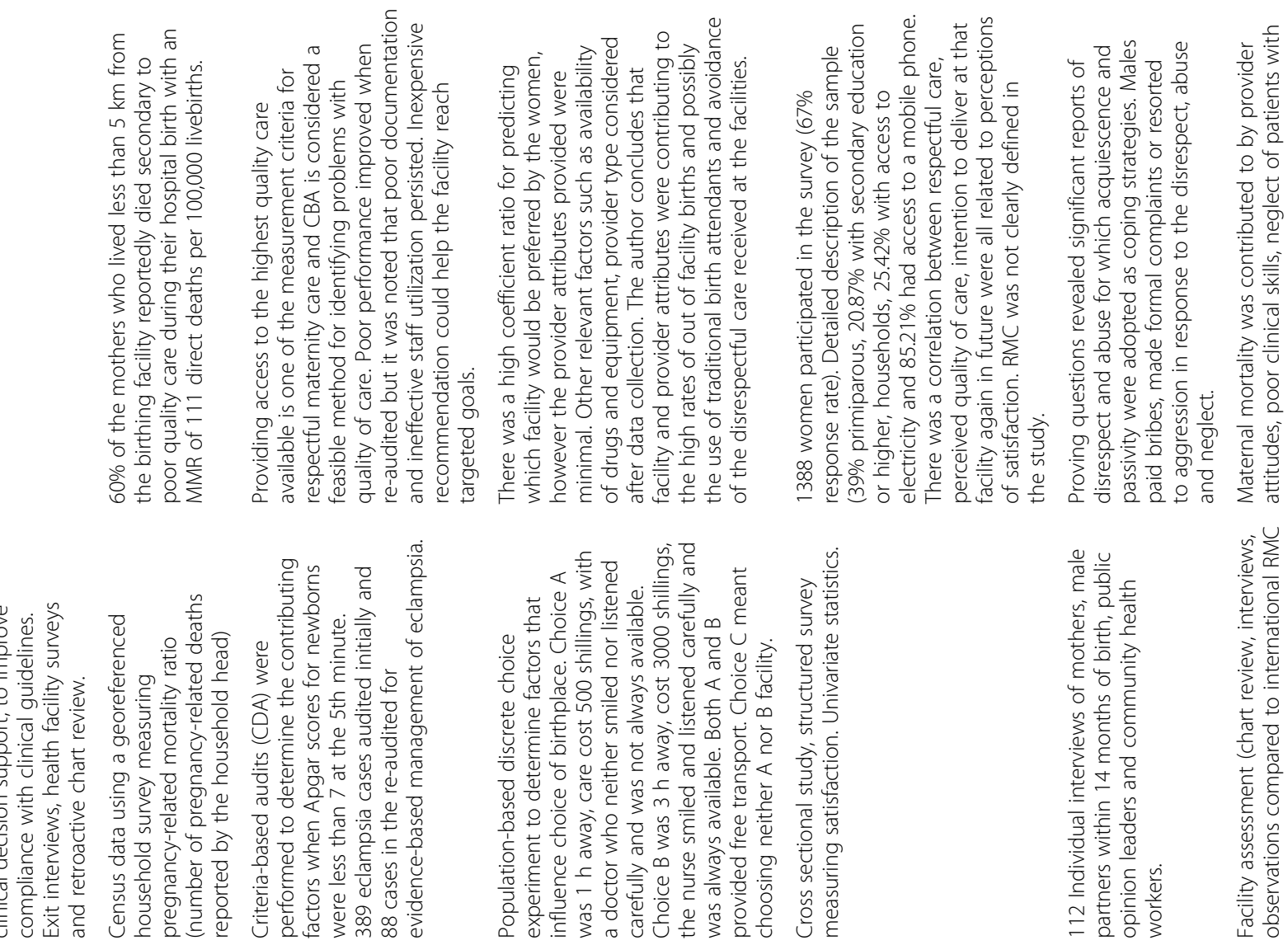

물를
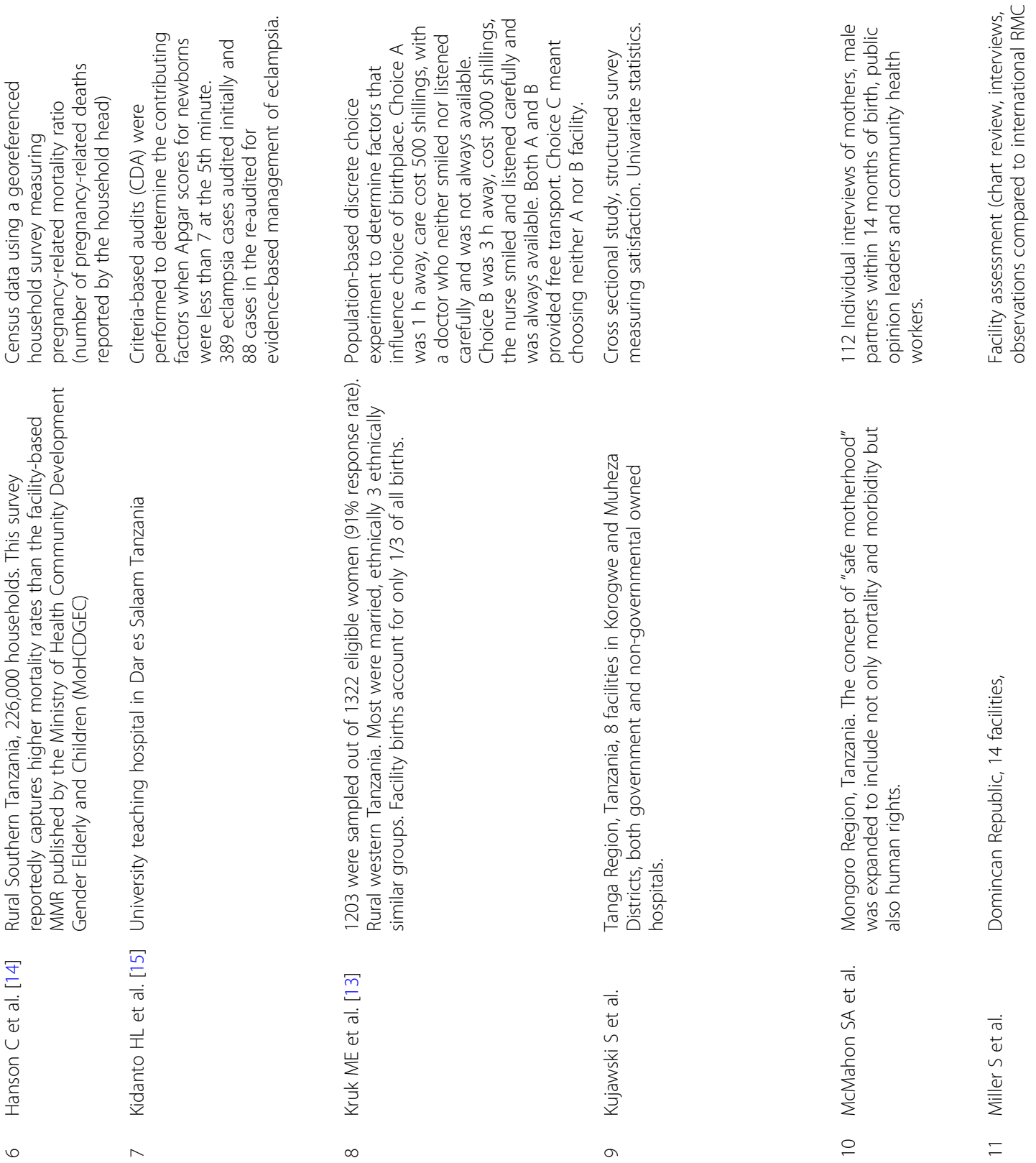

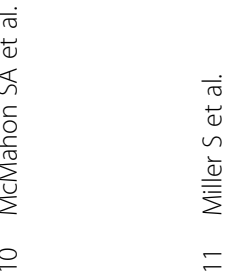




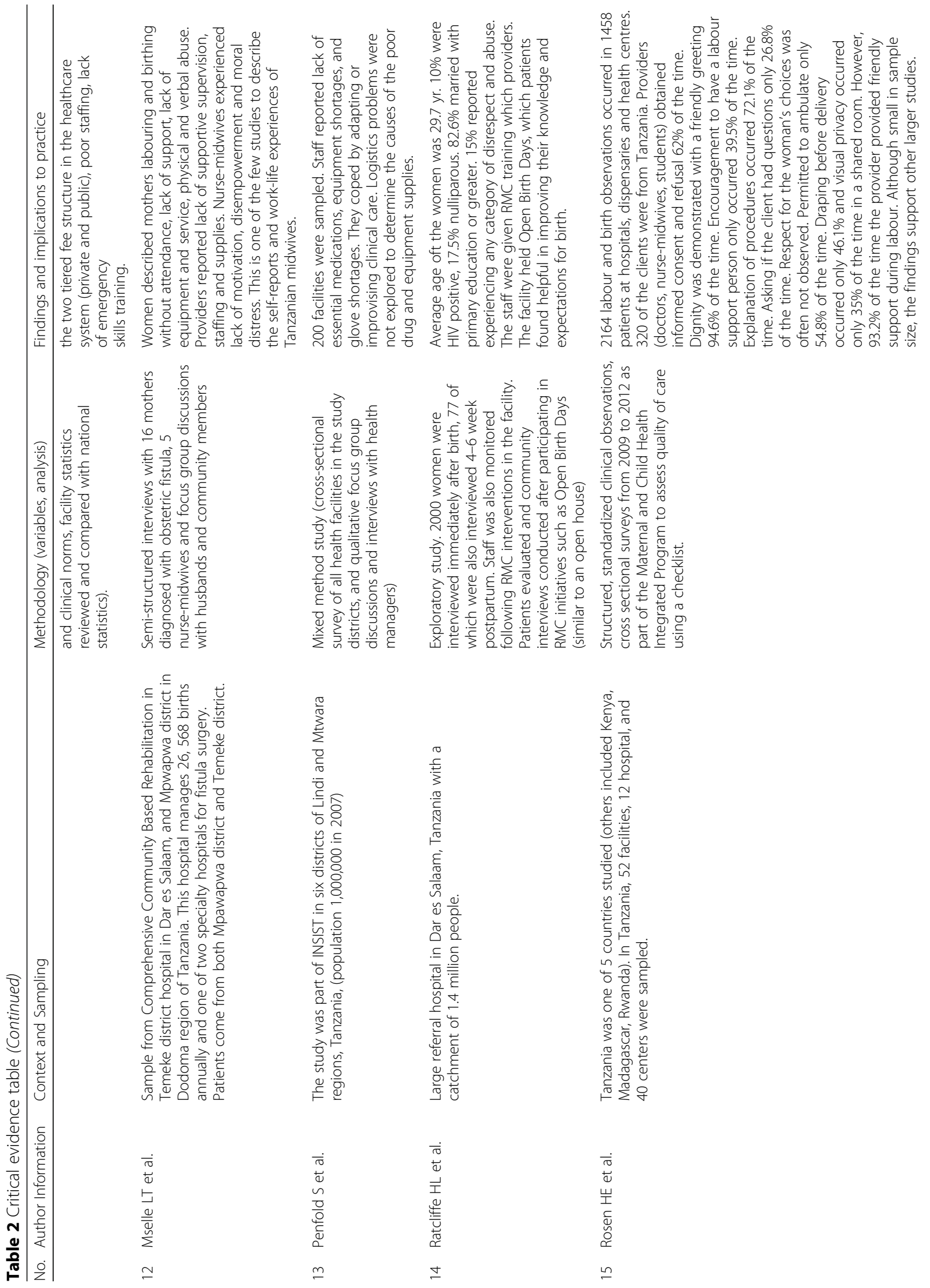




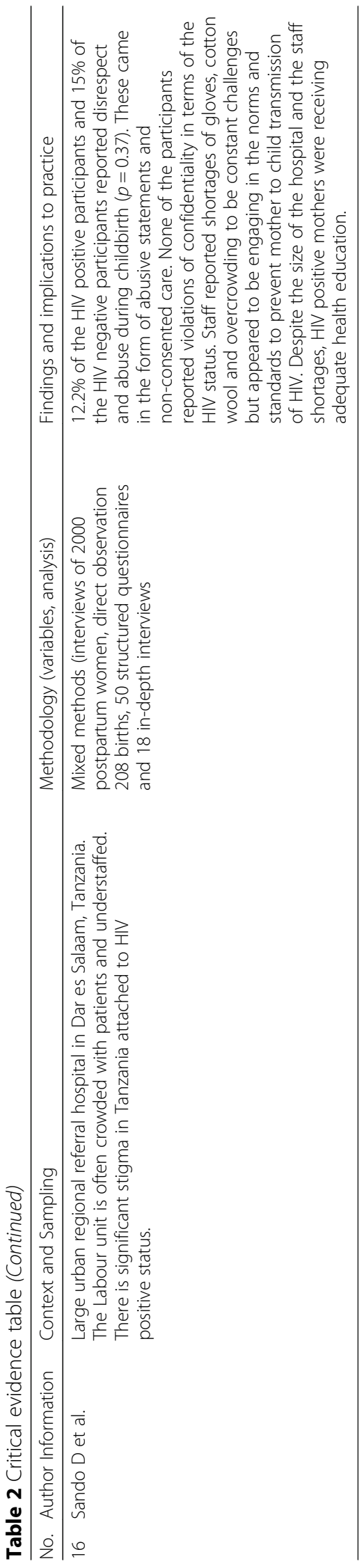


workers who are skilled in cultural sensitivity and respectful communication strategies might improve maternal satisfaction, service utilization and perinatal outcomes in Pakistan. In a mixed method study that included 52 Tanzanian facilities, Rosen et al. [7] observed that insufficient communication and information sharing by providers, delays in care, abandonment of laboring women, lack of a patient-centered approach by hospital administration and poor infrastructure contributed to disrespectful care (See Table 3).

Many authors note that disrespectful care is not well-studied, nor is it well-recorded, and there are methodological challenges to conducting this research
[23]. If each of the RMC domains is treated as categorical or dichotomous variable to describe its effect either on facility utilization or on perinatal outcomes, separating the effects of changes to each variable has yet to be designed into logistic regression models. Yet, research utilizing trained community health workers or respectful centering pregnancy models do not control for facility or infrastructure factors. Notwithstanding, there may be ethical dilemmas in purposely eliminating one of the seven factors in favour of examining another. Consequently, though constituting a higher order of evidence [24, 25], randomized control trials (RCTs) are problematic.

Table 3 Summary of RMC methodologies and frameworks

Type of RMC Research Question
Do health education interventions improve facility utilization?
Does disrespect and abuse correlate with facility utilization?
What is the incidence and prevalence of disrespectful care and abuse?
What types of abuse occur?
What are the perinatal outcomes/indicators in the facilities where
disrespect and abuse occur?

Describe the elements of disrespect and abuse

Do RMC-related community interventions improve perinatal outcomes? (deploying Lady Health or Community Health Workers)

Does strengthening one or more domains of RMC affect perinatal outcomes?

What do providers and families identify as important to quality, satisfying maternity care and desirable healthcare work environment?

Compare client's lived experience of respectful

versus disrespectful care

Describe the work-life experience of the healthcare workers when disrespect and abuse are occurring.

Describe the lived experience of vulnerable groups when disrespect, abuse or RMC occurs.

What are the barriers to provision of RMC and what are the recommendations Individual and focus group interviews of midwives for improving care quality?

What types of abuse occur?

Which providers perpetrate abuse? (MD, RN, RM, resident, staff MD, student midwife) What are their number of years of professional training, years of practice, amount of RMC training?

\begin{tabular}{|c|c|}
\hline Quantitative & Theoretical Framework \\
\hline \multicolumn{2}{|l|}{ Methodology } \\
\hline Quasi experimental before-and-after & $\begin{array}{l}\text { Community-based } \\
\text { participatory framework }\end{array}$ \\
\hline Correlational & Not usually stated \\
\hline $\begin{array}{l}\text { National health surveys } \\
\text { Institutional surveys } \\
\text { National household surveys } \\
\text { Demographic health surveys } \\
\text { Facility statistics } \\
\text { Population surveys/epidemiological } \\
\text { surveys }\end{array}$ & $\begin{array}{l}\text { RMC } \\
\text { Medical models } \\
\text { Public health models }\end{array}$ \\
\hline $\begin{array}{l}\text { Case control studies } \\
\text { Prospective closed cohort }\end{array}$ & $\begin{array}{l}\text { Critical human rights, } \\
\text { reproductive rights }\end{array}$ \\
\hline Clustered RCT & $\begin{array}{l}\text { Medical model } \\
\text { WHO and MDG focus }\end{array}$ \\
\hline $\begin{array}{l}\text { Correlational } \\
\text { Retrospective descriptive } \\
\text { Self-administered surveys }\end{array}$ & $\begin{array}{l}\text { Medical model } \\
\text { Public health models }\end{array}$ \\
\hline \multicolumn{2}{|l|}{ Qualitative } \\
\hline Exploratory & $\begin{array}{l}\text { Critical Human Rights, } \\
\text { reproductive rights }\end{array}$ \\
\hline $\begin{array}{l}\text { Phenomenological hermeneutics with } \\
\text { semi-structured interviews }\end{array}$ & $\begin{array}{l}\text { Human rights } \\
\text { Childbirth Rights } \\
\text { Critical Social Theory }\end{array}$ \\
\hline Focus groups & Resilience theory \\
\hline
\end{tabular}

RMC

Feminist version of poststructural interactionism

Mixed Methods

Institutional/rapid Assessment (including RMC

2-person expert observations, surveys, Human rights focus groups, semi-structured individual Childbirth rights interviews of staff and patients, facility check-lists based upon national professional standards and WHO standards, facility statistics MMR, IMR) 
This leaves us with observational, retrospective, case studies, and various qualitative studies to understand why midwives or mothers define some care as dignified or respectful while finding other types of care disrespectful. Women may be reluctant to share experiences of disrespectful care. One author notes that women may not divulge disrespectful care and that the language with which women describe disrespectful care may go unrecognized [26]. For example, in a qualitative study the women often responded positively when first asked about their birth experience generally. However, more careful probing would often reveal disrespectful care (such as "screaming" or "speaking roughly"). This underscores the necessity for a tangible definition of respectful care, such is provided in the seven domains, to allow for uniform documentation [13].

Table 2 summarizes methodologies used to examine all or some of the domains of respectful maternity care in the research reviewed between the years of 2000 and 2016. This foundational research has provided an excellent springboard for action research and quality improvement evaluation following RMC interventions. In the years to come, healthcare providers, policy makers and educators should anticipate curriculum development and post-service training to be informed by the emerging quality improvement research linked to RMC. Within these studies, vulnerable populations have been sampled, such as adolescent mothers [19, 27], mothers who are HIV positive [19, 20], mothers of lower socioeconomic status, discriminated ethnic groups or castes $[17,26]$, and new immigrant mothers [28], with particular emphasis on their experience of discriminatory beliefs, attitudes and practices [20].

Ratcliff et al. [6] describes the use of an educational program and workshop that involved strengthening many skills in two Tanzanian facilities. The aspects addressed included birth preparedness skills, patient-provider communication and provider-administrator communication skills. They found that patients reported increased feelings of empowerment and confidence during delivery. Providers reported increased job satisfaction and improved quality of care was recorded by external observers. Many researchers emphasize the need for RMC provider training which includes strategies for communication with the hospital administration regarding infrastructure and staffing needs as key elements [29].

A critical analysis of the literature reveals that increased access to high quality care will not necessarily improve outcomes without community engagement. Previously, global development was focused on increasing the numbers of facilities, the equipment, the numbers of providers, and modes of transportation, presumably to improve access to care [13, 20, 30-32]. However, mothers continued to avoid care due to disrespectful behaviors of the caregivers [18]. Mothers desired and/or were denied adequate informed consent $[18,19,28,33,34]$. They report that the provider failed to include them in decision-making process surrounding admission and plan of care. They report that they had little understanding of rationale for interventions [19, 34, 35]. It would be unfair to simply draw conclusions for a causative relationship between disrespectful care and lack of skill amongst providers. However, by hearing the lived work experiences of midwives in the Global South, valuable data has begun to emerge that indicate disrespectful care is a multifactorial phenomenon. Consequently, education of midwives solely, without changing the conditions of midwifery work might prove to be ineffective.

\section{The work-life of the midwife}

Researchers are attempting to document the conditions from which disrespectful care emerges. Midwives in the Global South described challenging shortages of equipment and staff $[19,36]$. They also expressed job dissatisfaction, low morale or motivation, significant desire to quit and inadequate training [34, 36-38]. The researchers cited these issues as barriers to caring for women adequately and deterrents to accessing care. Researchers explain that this weak infrastructure discourages respectful care $[19,36,38]$. (These studies also describe higher incidences of adverse outcomes such as maternal and newborn deaths).

Possibly, midwives who describe a sense of oppression or constraint due to the public and facility policies within which they work, may also be less likely to work efficiently or respectfully [39]. Therefore, rather than a punitive, oppressive approach, educators, researchers and policy-makers have addressed disrespectful care by building human resource capacity, by strengthening professional organizations and by educating midwives in low-resource countries. Furthermore, researchers such as Ratcliff et al. [6] encourage midwives not only to acquire attitudinal change and to adopt respectful maternity care skills, but also to emerge as leaders who challenge policy-makers, institutional administrators and politicians to strengthen the healthcare system and infrastructure that effects respectful maternity care so significantly. Notwithstanding, the process of becoming a change agent is not easy in the Tanzanian context due to the organizational system and culture, where midwives are so immersed in the work of midwifery that they describe being less informed and unable to advocate for themselves regarding their work-life. The next steps in research will require evaluation of the RMC strategies and interventions that have been employed since the 2015 challenges posed by the WHO, preferably including the perspectives of midwives [4]. 


\section{Leadership and change}

It is clear from a few Tanzanian studies that the midwives were attempting to address severe and urgent crises. In fact, Penfold and colleagues [29] noted that distressed staff in Tanzanian facilities coped with the unsatisfactory working conditions by dangerous risk-taking behaviours; including improvisation in the absence of functioning equipment or sufficient supplies, alternative forms of sterilization that are not evidence-based and shorten the life of the equipment, risking their own health and safety by avoiding infection control standards to perform life-saving procedures for patients (e.g., mouth-to-mouth resuscitation for newborns). It is unknown whether their patients or families received these efforts positively, and whether these efforts mitigated some of the perceptions of disrespect that reportedly deter families from using healthcare facilities [14]. Consequently, safe methods of addressing maternal and newborn mortality and morbidity need to be developed. Emerging evidence points to interventions such as education in crisis management, leadership and communication as integral to RMC training.

Clearly action research needs to measure the outcomes of clinical and social innovations employed in the low-middle-income countries (See Table 4). These innovations were in both Tanzania and South Sudan by some of the authors. Qualitative, substantive changes such as creating privacy drapes, using temporary privacy walls with drapes on intravenous poles, obtaining informed consent and refusal. The younger participants with 3-year diplomas and 4-year degrees tended to generate more innovative digital solutions such as an electronic form of the WHO mandated Partograph [40], however these creative ideas require start-up grants and major global health funding to implement.

The participants of the RMC workshops requested ongoing continuing education in RMC. They found the workshops cathartic for those who suffered post-traumatic grief after having engaged in or witnessed disrespect and abuse. They also found the workshops to be synergistic and empowering in terms of findings practical, low-cost, effective solutions to complex social situations, complicated by low resources and high risk clinical decision-making. Recommendations from the participants and consultants were to meet with ministry of health professionals, local midwifery educators and midwife preceptors in social innovation rounds to discuss common goals and troubleshoot for solutions over an interprofessional, informal gathering. In countries rife with high context cultural norms where meetings must be officiated by respected high ranking medical officers or government representatives, these meetings are essential if RMC initiatives are to be endorsed and ratified. Similarly, student midwives learning to apply evidence-informed care need the support of effective midwife allies who will model leadership and courage as they advocate for respectful care of vulnerable clients and culturally safe engagement with the community.

\section{Conclusion}

Defining disrespectful care in a tangible way with concrete examples will aid in research and intervention design, as well as the sharing of best practices and interventions. A

Table 4 Social and clinical innovations

\begin{tabular}{|c|c|}
\hline Social or Clinical Innovations Recommended & Organization who has Recommended These Interventions \\
\hline Open maternity days or open houses & Population Council \\
\hline Provider debriefing and psychosocial support & Population Council \\
\hline Redevelop partograph & $\begin{array}{l}\text { WRA adaptation as an RMC eval tool, UNFPA recommended modifications, } \\
\text { Jhpiego e-partograph (https://bmcpregnancychildbirth.biomedcentral.com/arti- } \\
\text { cles/10.1186/s12884-018-1760-y) }\end{array}$ \\
\hline Mediation program & Population Council \\
\hline Respectful Maternity Care training workshop & $\begin{array}{l}\text { WRA } \\
\text { Population Council } \\
\text { TAMA/CAM/Jhpiego partnership }\end{array}$ \\
\hline $\begin{array}{l}\text { Health Facility Management Board or Multidisciplinary Stakeholders } \\
\text { group (politicians, business, legal council, writers, journalists) }\end{array}$ & $\begin{array}{l}\text { Population Council } \\
\text { Midwives in TAMA RMC Workshops }\end{array}$ \\
\hline Elders meetings and community engagement strategies (teas) & Midwives in TAMA RMC Workshops \\
\hline Emergency Skills Workshops infused with RMC PBL & Midwives in TAMA RMC Workshops \\
\hline $\begin{array}{l}\text { Mediators appointed from laws school students, retired lawyers, } \\
\text { social workers }\end{array}$ & Midwives in TAMA RMC Workshops \\
\hline $\begin{array}{l}\text { Anteroom outside of delivery room where families may verbally } \\
\text { provide ongoing support to birthing/laboring mother }\end{array}$ & $\begin{array}{l}\text { CEPBU Community Health Centres, Burundi http://fr.allafrica.com/stories/ } \\
\text { 200703020713.html }\end{array}$ \\
\hline $\begin{array}{l}\text { Educate more mother/family friendly allies and champion in the } \\
\text { professional community }\end{array}$ & $\begin{array}{l}\text { NGO "Save the Mothers" founded an interdisciplinary Master of Public Health } \\
\text { Leadership in Uganda. https://www.savethemothers.org/what-we-do/degree- } \\
\text { program/ }\end{array}$ \\
\hline
\end{tabular}

Abbreviations: CAM Canadian Association of Midwives, CEPBU La Communauté des Eglises de Pentecôte du Burundi, NGO Non-governmental organization, PBL Problem-based learning, TAMA Tanzanian Midwives Association, UNFPA United National Population Fund, WRA White Ribbon Alliance 
general terminology and taxonomy of RMC has clearly emerged over the past two decades. This is facilitating knowledge exchanges, and it is also helping to aid researchers and practitioners to gain resources which promote RMC.

However, within this broader understanding of how RMC impacts birth outcomes and maternal mortality, we note the importance of centering the birthing person and their inherent dignity in its own right, regardless of the outcomes, lest we exploit respectful care as a fleeting ploy to pacify hospital administrators. We noted that most studies linked disrespectful care to low uptake of skilled birth attendance and negative health outcomes. It is therefore essential to speak of both the impact on birth outcomes (including mortality), as well as the important personal and individual lived experience of the birthing mother. Importantly, it is the experience that the birthing mother brings (biological, ancestral, and lived) that are undermined when personal choice is not respected in the birthing environment (See Table 1, Domain 4). We believe that most authors recognize this implicitly, however, it is worth articulating and repeating.

Table 2 describes the various types of research questions that define the RMC problems faced by healthcare providers in low-resource countries. Future research questions need to measure the effectiveness of interventions directed at all seven domains of RMC. Researchers posit that ongoing structural, attitudinal and healthcare system changes will significantly affect facility utilization, perinatal outcomes, healthcare provider retention and the overall quality of maternity care in the Global South $[5,18,28]$. Tanzania, the recipient of many global development grants, is poised to pilot many of the recommendations emerging from the research (See Table 2).

\section{Abbreviations}

CEPBU: La Communauté des Eglises de Pentecôte du Burundi; IMR: Infant mortality rate; MDG: Millenium Development Goals; MMR: Maternal mortality ratio; PBL: Problem-based learning; $R C T$ : Randomized controlled trial; RMC: Respectful maternity care; TAMA: Tanzania Midwives Association; WHO: World Health Organization

\section{Acknowledgements}

More and Better Midwives for Rural Tanzania project (Tanzanian Midwives Association, Canadian Association of Midwives, Jhpiego, and Amref), Ministry of Health Community Development Gender Elderly and Children, President Office - Regional Administration and Local Government, Global Affairs Canada.

All the practicing midwives are under the President's Office - Regional Administration and Local Government that have authority to allow take part in the trainings and other related activities.

\section{Funding}

Faculty of Community Services, Ryerson University Publication Grant of $\$ 1500$ CAD.

\section{Authors' contributions}

KWM and JR performed the literature review. AS, SS and LE were major contributors in writing the manuscript. All authors read and approved the final manuscript.
Ethics approval and consent to participate

Not applicable

\section{Consent for publication}

Not applicable

\section{Competing interests}

The authors declare that they have no competing interests.

\section{Publisher's Note}

Springer Nature remains neutral with regard to jurisdictional claims in published maps and institutional affiliations.

\section{Author details}

${ }^{1}$ Midwifery Education Program, Ryerson University, 350 Victoria Street, Toronto, ON M5B 2K3, Canada. ${ }^{2}$ Tanzanian Midwives Association, P.O. Box 65524, Muhimbili Dar Es Salaam, Tanzania. ${ }^{3}$ Canadian Association of Midwives, 2330 Notre-Dame W., Suite 300, Montreal, Quebec H3J 1N4, Canada.

Received: 5 December 2017 Accepted: 3 September 2018

Published online: 03 October 2018

\section{References}

1. IBRD-IDA WBG. Country and lending groups. 2015. Available from: http://data.worldbank.org/about/country-and-lending-groups. Accessed 16 Sept 2018.

2. USAID. Maternal and child health Tanzania. 2017. Available from: https:// www.usaid.gov/sites/default/files/documents/1860/Maternal_and_Child_ Health_Fact_Sheet_2017_FINAL.pdf. Accessed 16 Sept 2018.

3. The White Ribbon Alliance for Safe Motherhood. Respectful Maternity Care: The Universal Rights of Childbearing Women. White Ribb. Alliance Safe Mother. 2011;1-6. Available from: http://whiteribbonalliance.org/wpcontent/uploads/2013/10/Final_RMC_Charter.pdf. Accessed 15 Sept 2018.

4. Organization WH. Sexual health, human rights and the law. World Health Organization; 2015. Available from: http://apps.who.int/iris/bitstream/10665/ 175556/1/9789241564984_eng.pdf?ua=1. Accessed 15 Sept 2018.

5. Bowser D, Hill K. Exploring evidence for disrespect and abuse in facilitybased childbirth. Bost: USAID-TRAction Proj. Harvard Sch. Public Heal; 2010.

6. Ratcliffe HL, Sando D, Lyatuu GW, Emil F, Mwanyika-Sando M, Chalamilla G, et al. Mitigating disrespect and abuse during childbirth in Tanzania: an exploratory study of the effects of two facility-based interventions in a large public hospital. Reprod Health. 2016;13(1):79.

7. Rosen HE, Lynam PF, Carr C, Reis V, Ricca J, Bazant ES, et al. Direct observation of respectful maternity care in five countries: a cross-sectional study of health facilities in East and Southern Africa. BMC Pregnancy Childbirth. 2015;15:306. Available from: https://doi.org/10.1186/s12884-015-0728-4

8. Shakibazadeh E, Namadian M, Bohren MA, Vogel JP, Rashidian A, Pileggi N, et al. Respectful care during childbirth in health facilities globally: a qualitative evidence synthesis. [cited 2018 Aug 14]; Available from: www.bjog.org.

9. Duysburgh E, Zhang W-H, Ye M, Williams A, Massawe S, Sié A, et al. Quality of antenatal and childbirth care in selected rural health facilities in Burkina Faso, Ghana and Tanzania: similar finding. Trop Med Int Heal. 2013;18:534-47. [cited 2017 Nov 29] Available from: http://doi.wiley. com/10.1111/tmi.12076.

10. Mselle LT, Moland KM, Mvungi A, Evjen-Olsen B, Kohi TW. Why give birth in health facility? Users' and providers' accounts of poor quality of birth care in Tanzania. BMC Health Serv Res. 2013;13:174.

11. Sando D, Ratcliffe H, McDonald K, Spiegelman D, Lyatuu G, MwanyikaSando $M$, et al. The prevalence of disrespect and abuse during facility-based childbirth in urban Tanzania. BioMed Central. BMC Pregnancy Childbirth. 2016 Aug 19;16:236. https://doi.org/10.1186/s12884-016-1019-4.

12. Sheriff FG, Manji KP, Manji MP, Chagani MM, Mpembeni RM, Jusabani AM, et al. Latent tuberculosis among pregnant mothers in a resource poor setting in Northern Tanzania: a cross-sectional study. BMC Infect Dis. 2010; 10:52. available at https://bmcinfectdis.biomedcentral.com/articles/10.1186/ 1471-2334-10-52. Accessed 9 Sept 2018.

13. Kruk ME, Paczkowski M, Mbaruku G, De Pinho H, Galea S. Women's preferences for place of delivery in rural Tanzania: a population-based discrete choice experiment. Am J Public Health. 2009;99:1666-72.. 
14. Kujawski S, Mbaruku G, Freedman LP, Ramsey K, Moyo W, Kruk ME. Association between disrespect and abuse during childbirth and women's confidence in health facilities in Tanzania. Matern Child Health J. 2015;19:2243-50.

15. Kidanto $\mathrm{HL}$, Wangwe $\mathrm{P}$, Kilewo $\mathrm{CD}$, Nystrom L, Lindmark G. Improved quality of management of eclampsia patients through criteria based audit at Muhimbili National Hospital, Dar es Salaam, Tanzania. Bridging the quality gap. BMC Pregnancy Childbirth. 2012;12:134.

16. Miller S, Cordero M, Coleman AL, Figueroa J, Brito-Anderson S, Dabagh R, et al. Quality of care in institutionalized deliveries: the paradox of the Dominican Republic. Int. J. Gynecol. Obstet. 2003;82:89-103. [cited 2017 Nov 1]

17. Singh PK, Rai RK, Alagarajan M, Singh L. Determinants of maternity care services utilization among married adolescents in rural India. PLoS One. 2012;7. Retrieved from https://bmcpregnancychildbirth.biomedcentral.com/ articles/10.1186/s12884-018-1760-y. Accessed 16 Sept 2018.

18. Abuya T, Warren CE, Miller N, Njuki R, Ndwiga C, Maranga A, Mbehero F, Njeru A, Bellows B. Exploring the prevalence of disrespect and abuse during childbirth in Kenya. PloS one. 2015;10(4):e0123606.

19. Bohren MA, Vogel JP, Hunter EC, Lutsiv O, Makh SK, Souza JP, et al. The mistreatment of women during childbirth in health facilities globally: a mixed-methods systematic review. PLoS Med. 2015;12:e1001847.

20. Sando D, Kendall T, Lyatuu G, Ratcliffe H, McDonald K, Mwanyika-Sando M, et al. Disrespect and abuse during childbirth in Tanzania: are women living with HIV more vulnerable? J Acquir Immune Defic Syndr. 2014;67(Suppl 4): S228-34. Available from: https://www.ncbi.nlm.nih.gov/pmc/articles/ PMC4251905/. Accessed 9 Sept 2018

21. Prost A, Colbourn T, Seward N, Azad K, Coomarasamy A, Copas A, et al. Women's groups practising participatory learning and action to improve maternal and newborn health in low-resource settings: a systematic review and meta-analysis. Lancet. 2013;381:1736-46.

22. Bhutta ZA, Soofi S, Cousens S, Mohammad S, Memon ZA, Ali I, et al. Improvement of perinatal and newborn care in rural Pakistan through community-based strategies: a cluster-randomised effectiveness trial. Lancet. 2011:377:403-12. [cited 2018 Sept 1] Available from: https://www. sciencedirect.com/science/article/pii/S014067361062274X.

23. Miller $\mathrm{S}$, Abalos E, Chamillard M, Ciapponi A, Colaci D, Comandé D, et al. Beyond too little, too late and too much, too soon: a pathway towards evidence-based, respectful maternity care worldwide. Lancet. 2016;388:2176-92.

24. Kendall S. Evidence-based resources simplified. Can. Fam. Physician. 2008;54: 241-3. College of Family Physicians of Canada [cited 2017 Nov 25] Available from: http://www.cfp.ca/content/54/2/241.short. Accessed 9 Sept 2018.

25. Murad MH, Asi N, Alsawas M, Alahdab F. New evidence pyramid. Evid. Based. Med. 2016;21:125-7. BMJ Publishing Group [cited 2017 Nov 25] Available from: https://ebm.bmj.com/content/early/2016/06/23/ebmed2016-110401?utm_source=trendmd\&utm_medium=cpc\&utm_campaign= bmjopen\&trendmd-shared=1\&utm_content=Journalcontent\&utm_term = TrendMDPhase4. Accessed 9 Sept 2018.

26. McMahon SA, George AS, Chebet JJ, Mosha IH, Mpembeni RN, Winch PJ. Experiences of and responses to disrespectful maternity care and abuse during childbirth; a qualitative study with women and men in Morogoro Region, Tanzania. BMC pregnancy and childbirth. 2014;14(1):268. Available from: https://bmcpregnancychildbirth.biomedcentral.com/articles/10.1186/ 1471-2393-14-268. Accessed 9 Sept 2018.

27. Manandhar DS, Osrin D, Shrestha BP, Mesko N, Morrison J, Tumbahangphe KM, Tamang S, Thapa S, Shrestha D, Thapa B, Shrestha JR. Effect of a participatory intervention with women's groups on birth outcomes in Nepal: clusterrandomised controlled trial. The Lancet. 2004;364(9438):970-9. Available at: https://www.sciencedirect.com/science/article/pii/S0140673604170219. Accessed 9 Sept 2018.

28. Small R, Yelland J, Lumley J, Brown S, Liamputtong P. Immigrant women's views about care during labor and birth: An Australian study of Vietnamese, Turkish, and Filipino women. Birth Issues Perinat. Care. 2002;29:266-77.

29. Penfold S, Shamba D, Hanson C, Jaribu J, Manzi F, Marchant T, et al. Staff experiences of providing maternity services in rural southern Tanzania - a focus on equipment, drug and supply issues. BMC Health Serv. Res. 2013;13: 61. BioMed Central [cited 2017 Nov 1] Available from: http://www.ncbi.nlm. nih.gov/pubmed/23410228

30. Hanson C, Cox J, Mbaruku G, Manzi F, Gabrysch S, Schellenberg D, et al. Maternal mortality and distance to facility-based obstetric care in rural southern Tanzania: a secondary analysis of cross-sectional census data in 226000 households. Lancet Glob. Heal. 2015;3:e387-95. Elsevier [cited
2017 Nov 28] Available from: http://www.sciencedirect.com/science/ article/pii/S2214109X15000480

31. ten Hoope-Bender P, Lopes STC, Nove A, Michel-Schuldt M, Moyo NT, Bokosi M, et al. Midwifery 2030: a woman's pathway to health. What does this mean? Midwifery. 2016:32:1-6. Available from: https://www.sciencedirect.com/science/ article/pii/S0266613815002855. Accessed 9 Sept 2018.

32. Rockers PC, Wilson ML, Mbaruku G, Kruk ME. Source of antenatal care influences facility delivery in rural Tanzania: a population-based study. Maternal and Child Health Journal. 2009;13(6):879. Available at https://link. springer.com/article/10.1007/s10995-008-0412-7. Accessed 9 Sept 2018.

33. Lozano R, Wang H, Foreman KJ, Rajaratnam JK, Naghavi M, Marcus JR, et al. Progress towards millennium development goals 4 and 5 on maternal and child mortality: an updated systematic analysis. Lancet. 2011;378:1139-65.

34. Miller S, Cordero M, Coleman AL, Figueroa J, Brito-Anderson, S, Dabagh, R.... $\&$ Nunez M. Quality of care in institutionalized deliveries: the paradox of the Dominican Republic. Int J Gynecol Obstet. 2003;82:89-103.

35. Oyerinde K, Harding Y, Amara P, Garbrah-Aidoo N, Kanu R, Oulare M, et al. A Qualitative Evaluation of the Choice of Traditional Birth Attendants for Maternity Care in 2008 Sierra Leone: Implications for Universal Skilled Attendance at Delivery. Matern Child Health J. 2013;17:862-8.

36. Knight HE, Self A, Kennedy SH. Why Are Women Dying When They Reach Hospital on Time? A Systematic Review of the "Third Delay." PLoS One; 2013;8:e63846. available at: https://journals.plos.org/plosone/article?id=10. 1371/journal.pone.0063846. Accessed 9 Sept 2018.

37. Bohren MA, Vogel JP, Tunçalp Ö, Fawole B, Titiloye MA, Olutayo AO, et al. Mistreatment of women during childbirth in Abuja, Nigeria: a qualitative study on perceptions and experiences of women and healthcare providers. Reprod Heal. 2017;141:14.

38. Bone nberger M, Aikins M, Akweongo P, Wyss K. The effects of health worker motivation and job satisfaction on turnover intention in Ghana: a crosssectional study. Hum Resour Health. 2012;12:43. Available at https://humanresources-health.biomedcentral.com/articles/10.1186/1478-4491-12-43. Accessed 9 Sept 2018.

39. Wilson-Mitchell K. Care of the uninsured migrant family in the greater Toronto area. Can J Midwifery Res Pr. 2013;12:38-41.

40. Litwin LE, Maly C, Khamis AR, Hiner C, Zoungrana J, Mohamed K, Drake M, Machaku M, Njozi M, Muhsin SA, Kulindwa YK. Use of an electronic Partograph: feasibility and acceptability study in Zanzibar, Tanzania. BMC pregnancy and childbirth. 2018;18(1):147. Available at https://bmcpregnancychildbirth. biomedcentral.com/articles/10.1186/s12884-018-1760-y. Accessed 15 Sept 2018.

\section{Ready to submit your research? Choose BMC and benefit from:}

- fast, convenient online submission

- thorough peer review by experienced researchers in your field

- rapid publication on acceptance

- support for research data, including large and complex data types

- gold Open Access which fosters wider collaboration and increased citations

- maximum visibility for your research: over $100 \mathrm{M}$ website views per year

At $\mathrm{BMC}$, research is always in progress.

Learn more biomedcentral.com/submissions 